\title{
LA FORMACIÓN POR EL ARTE
}

Alfonso López Quintás*

SÍNTESE - $O$ autor, num primeiro momento, examina com profundidade a eficácia pedagógica da obra de arte seja no campo da música, da arquitetura, da pintura ou da escultura; num segundo momento, passa a estabelecer as condiçōes para que uma obra de arte seja fecunda no campo pedagógico.
ABSTRACT - Firstly, the author thoroughly examines the pedagogic efficiency of the work of art, in the fields of music, architecture, painting or sculpture. Secondly, he establishes the necessary conditions so that a piece of art becomes useful in educational matters.

El gran filósofo, dramaturgo y músico francés, Gabriel Marcel, nos dejó un testimonio sorprendente acerca de su conversión religiosa: "Tengo que anotar aquíescribe - la importancia excepcional de Juan Sebastian Bach. Las Pasiones y Cantatas: en el fondo, la vida cristiana me ha venido a través de esto. Los encuentros han tenido un papel capital en mi vida. He conocido seres en los cuales sentía tan viva la realidad de Cristo que ya no me era lícito dudar". "Nadie duda - afirma en otro lugar - que la función espiritual de la música consiste, en el fondo, en devolver el hombre a si mismo. Devolver el hombre a si mismo es, en verdad, devolverlo a Dios". $^{2}$

¿Cómo se explica esta eficacia pedagógica de la experiencia artística: la musical, la arquitectónica, la pictórica, la escultórica...? Para contestar de forma radical a esta pregunta, debemos recordar, siquiera esquemáticamente, algunas condiciones básicas del desarrollo humano y advertir que el conocimiento profundo de las mismas nos viene facilitado en sumo grado por las experiencias artísticas, cuando las sabemos vivir y comprender en su articulación interna.

\section{1 - La fecundidad de la obra de arte para la formación humana}

La Ciencia actual - singularmente la Biología - destaca que el hombre es "un ser de encuentro", un ser que vive como persona, se desarrolla y perfecciona como tal realizando encuentros con las realidades de su entorno. Estas realidades pueden ser nuestras compañeras de juego y de encuentro si las vemos no como "objetos"

* Universidad Complutense

1 Apud Ch. Moeller: Literatura del siglo XX y Cristianismo, Gredos, Madrid 1960, vol. IV, p. 296.

2 Cf L'esthétique musicale de Gabriel Marcel, Aubier, Paris 1980, p. 58.

\begin{tabular}{|l|l|l|l|l|l|}
\hline VERITAS & Porto Alegre & v. 40 & $\mathrm{n}^{2} 158$ & Junho 1995 & p. 193-212 \\
\hline
\end{tabular}


sino como "ámbitos". Nada más importante para la formación humana que descubrir la existencia de los "ámbitos de realidad" y sus diferentes clases. El arte nos facilita al máximo este descubrimiento.

Ahora bien, para ver las realidades como ámbitos, no sólo como objetos manipulables, se requiere una actitud de respeto y colaboración. Colaborar implica sentirse ob-ligado a realidades que constituyen para uno una especie de norma y cauce de acción. Si malentendemos la relación libertad-norma como un dilema, no podemos tener capacidad creativa suficiente para fundar relaciones fecundas con otras realidades.

Es decisivo notar que la creatividad humana es siempre dual, implica un sujeto dotado de ciertas potencias y un entorno capaz de otorgarle diversas posibilidades. Una persona puede estar muy bien dotada, ostentar unas potencias sobresalientes, pero a solas no puede ser creativa. Necesita recibir posibilidades de fuera, es decir, de realidades que en principio le son distintas, distantes, externas, estrañas y ajenas. El que interprete el esquema dentro-fuera como un dilema será incapaz de adivinar que es posible convertir lo distinto, distante, externo y extraño en intimo, sin dejar de ser distinto. Tal incapacidad le imposibilita para asumir activamente las posibilidades que le vengan ofrecidas. Esa asunción activa es la creatividad.

Cuando un joven se percata de que le es posible convertir lo distinto-distante en distinto-intimo da un paso de gigante hacia la madurez. En efecto, el ser humano desarrolla cabalmente su personalidad cuando sabe convertir en intimas las realidades externas y ajenas y fundar así con ellas un campo de libre juego, de entreveramiento fecundo, es decir: de encuentro.

Esta forma de entreveramiento constituye una experiencia reversible sumamente fecunda: da lugar a modos de unidad tan elevados que superan la escisión entre el aquí y el allí, el dentro y el fuera, lo cerradamente mío y lo crispadamente tuyo. Tal superación abre la posibilidad de pensar de forma relacional, y liberarse de la angostura del objetivismo sin caer en el subjetivismo relativista.

Esta liberación en el estilo de pensar amplía de modo insospechado nuestra idea básica de conocimiento, de verdad, de realidad y de hombre. Cómo se realiza de hecho esta ampliación y aquella superación no es fácil de descubrir por uno mismo. Pensemos en lo que significa ser autónomo y ser heterónomo. Lo primero indica regir la conducta en virtud de criterios propios, elaborados por uno mismo en su interioridad, no recibidos de fuera. Ser heterónomo significa guiarse en la vida por normas recibidas del exterior. ¿Podemos ser al mismo tiempo autónomos y heterónomos, o debemos escoger entre ambas conductas? Si no tenemos claridad acerca de esta cuestión, no estamos formados, no tenemos seguridad ninguna de acertar con la conducta justa y desarrollarnos debidamente como personas. En cualquier caso no debemos preocuparnos, sin duda somos capaces de realizar alguna experiencia artística y verla por dentro, en su estructura interna. Esforcémonos en hacerlo, y veremos cómo se nos ilumina la respuesta adecuada a esa decisiva cuestión y a todas las otras que implica nuestro proceso de maduración personal.

Explanemos, uno a uno, de forma rápida pero lo más precisa posible, los puntos a que he aludido anteriormente. 


\section{1 - El descubrimiento de los "ámbitos de realidad"}

A nuestro alrededor hay casas, tierras, rocas, cosas de diversos tipos. Aparecen ahi, enfrente de nosotros, como algo distinto de nuestro ser. Estar enfrente se dice en latín objacere, verbo del que se deriva ob-jicere, cuyo participio es ob-jectum. A todas las realidades que están frente al hombre y pueden ser analizadas por éste sin comprometer su propio ser las llamamos objetos. Son realidades objetivas. Estas realidades pueden ser medidas, pesadas, agarradas con la mano, situadas en el espacio, dominadas, manejadas.

Pero en el mundo existen realidades que son, en un aspecto, delimitables, asibles, pesables, dominables y manejables, y en otro no. Con una cinta métrica puedo medir fácilmente las dimensiones de una persona: el alto y el ancho. Pero lo que abarca en diversos aspectos - el ético, el afectivo, el profesional, el estético, el religioso - no lo puedo delimitar. Ni ella misma podría decirme exactamente hasta dónde llega, por ejemplo, su influjo sobre los demás y el de los demás sobre ella. "¿Dónde termina el que ama? ¿Dónde empieza el ser amado?", preguntaba una mujer a su esposo en un drama de Gabriel Marcel. El amor es algo real, y lo mismo el influjo que ejercemos unos sobre otros, pero su realidad no es del mismo tipo que la de los objetos; tiene un alcance mayor y escapa en buena medida a la vista, al tacto, al cálculo preciso. Pero puede de alguna manera imaginarse.

La persona humana se configura y desarrolla creando vínculos de diverso orden con multitud de realidades: la familia, el colegio, el pueblo, el paisaje, la tradición, las amistades, las obras culturales, la vida profesional, los valores... Esos vínculos suelen suponer un influjo mutuo y dan lugar a experiencias reversibles. Esta trama de experiencias constituye un gran campo de juego, en el cual la persona va adquiriendo un modo de ser peculiar, una personalidad cada vez más definida, una especie de segunda naturaleza. La persona humana no se reduce, por tanto, a objeto; constituye todo un campo o ámbito de realidad.

Esta condición de ámbito no la presentan sólo las personas. También la osten$\tan$ muchas realidades de nuestro derredor. Un piano, como mueble, es un objeto. Como instrumento, no. En cuanto mueble, se halla ahí frente a mí; puedo tocarlo, medir sus dimensiones, comprobar su peso, manejarlo a mi antojo - ponerlo en un sitio o en otro. Como instrumento, sólo existe para mí si sé hacer juego con él, si soy capaz de asumir las posibilidades que me ofrece de crear formas sonoras. Al entrar en juego con el piano, éste deja de estar fuera de mí; se une conmigo en un mismo campo de juego: en el campo de juego artístico que es la obra interpretada. Yo no puedo hacer con el piano lo que quiero; debo atenerme a su condición peculiar y a las características de la obra que toco en él. Esto es sumamente importante. Las realidades que no son meros objetos nos ofrecen posibilidades de juego, es decir, posibilidades para actuar de manera creativa, y, en cuanto nos las ofrecen, tienen cierta iniciativa, y merecen un trato respetuoso. Si no las respetamos, las rebajamos de condición, las tomamos como meros objetos, y con ello nos cerramos a las posibilidades que nos ofrecen y anulamos toda posibilidad de conocerlas.

Multitud de realidades de nuestro entorno presentan un aspecto de objetos, pero, vistas en la trama de la vida humana, se manifiestan también como ámbitos. Un barco puede ser pesado, medido, tocado, situado en el tiempo y en el espacio. 
Tiene las condiciones propias de los objetos. Pero, además de esto y en un nivel superior, ese barco concreto nos ofrece toda una serie de posibilidades: pasear, comer, dormir, pescar, navegar... Este tipo de realidades que no sólo se prestan a ser manejadas y dominadas sino que ofrecen posibilidades de acción a quien se relaciona con ellas en orden a realizar un proyecto que ha elaborado con su imaginación creadora las considero también como ámbitos de realidad o sencillamente ámbitos. Los ámbitos están delimitados como los objetos, pero se abren a otras realidades; pueden ser afectados por la acción de otros seres y, a la vez, ejercen un influjo sobre ellos; abarcan cierto campo a pesar de su delimitación. Un ejemplar de un libro, por ser material, pesa, está circunscrito a unos límites, es susceptible de manejo, puede deteriorarse. Pero, en cuanto obra literaria, nos abre a diversos horizontes de vida, plasma procesos, expresa sentimientos, incentiva la imaginación, transmite conocimientos... En una palabra: es fuente de posibilidades y origen de iniciativas. Constituye todo un ámbito de realidad.

Lo antedicho nos permite ver a una nueva luz mil y una realidades de la vida cotidiana. Citemos algunas para ampliar nuestro campo de visión y comprender seguidamente la gran función formativa del arte.

\section{2 - Diversos tipos de ámbitos}

El lugar en el que se vive es una realidad objetiva. El hogar que es fundado por dos esposos constituye un ámbito, un campo de juego cargado de virtualidades y posibilidades.

El lenguaje, visto como medio para comunicarse, parece reducirse a mero objeto. Si acertamos a verlo como un campo de significación y de luz que abre al hombre indefinidas posibilidades de comprensión y expresión, nos aparece como un ámbito. Así lo comprendió Kayrol al afirmar que "las palabras son moradas".

De modo análogo, las diversas formas de juego y de trabajo son ámbitos, campos de posibilidades de acción cargada de sentido. Consiguientemente, los papeles que el hombre puede desempenar en su juego vital son ámbitos. Y lo mismo las figuras que expresan acontecimientos, sucesos que implican un mundo complejodebido a la confluencia de distintas realidades 0 aspectos de la realidad - y abren campos nuevos de posibilidades. Piénsese, por ejemplo, en el "encuentro de Jacob y Rebeca", "la muerte de Julio César", la "Úitima Cena", "la Crucifixión", "Napoleón atravesando los Alpes"...

Han de ser vistos, asimismo, como ámbitos las realidades o sucesos que suponen un campo de interacción: el brotar de la primavera, el declinar del otoño, un campo de olivos, un grupo de saltimbanquis, un payaso, una barca pesquera o de recreo, un naufragio, una pareja de amantes, un sembrador, unas manos orantes, un anciano que medita junto a un cirio que arde...

Los sucesos que tejen la trama de la vida social significan un entreveramiento de realidades que abre diversas posibilidades a la acción humana. Basta analizar lo que implica dictar sentencia, hacer una promesa, inaugurar una red vial, consagrar un templo... Un edificio se convierte en templo cuando en él se encuentran por primera vez los creyentes que lo han edificado y el dios al que adoran. Tales sucesos han de ser considerados como ámbitos. 
Algo semejante acontece con las obras culturales. Cada una de ellas viene a ser un punto de confluencia de diversas realidades y ofrece al hombre un elenco de posibilidades bien definidas. Ahondemos en lo que implica una casa, una calle, una plaza, una ciudad, un puente, un monumento, unas botas de campesino, un camino, un jardín... Cada una de estas realidades culturales es una encrucijada. En ella se entreveran y vibran diversos seres. Por ejemplo, una plaza ha de ser vista no como un mero vacío entre las casas aglomeradas, sino como el lugar de confluencia de diversas calles y el punto de encuentro de quienes habitan en ellas. Originalmente, una plaza era un lugar de encuentro, no de mero tránsito y huída, como sucede hoy. Ello explica que la plaza, como realidad cultural, ocupe un lugar destacado en el mundo de la pintura de artistas tan notables como Canaletto y Guardi. Un camino no se reduce a una forma sinuosa que se abre paso entre la fronda de un bosque. Es un lugar de comunicación, un vínculo entre pueblos y personas. Por eso desborda simbolismo, y fue plasmado en grandes obras pictóricas.

En su breve y densa obra El origen de la obra de arte, ${ }^{3}$ Heidegger muestra de forma penetrante que en las "Botas de campesina" de Van Gogh se hace presente la humedad de la tierra, la dureza del trabajo en el campo, la fatiga de los pasos laboriosos..., toda una trama de realidades y circunstancias. Esta obra de arte no representa una mera figura; da cuerpo sensible a un mundo peculiar, un ámbito formado por un tejido de realidades y relaciones.

Cuando el ser humano adopta en la vida una actitud creadora, está convirtiendo constantemente los objetos y los meros espacios en ámbitos. Toma una simple tabla, píntala a cuadros blancos y negros, sitúa encima de ellas unas figuras de ajedrez, y la habrás convertido de objeto en ámbito. El niño pone una escoba entre sus piernas y se echa a correr. Con ello transforma un objeto en ámbito.

\section{3 - El arte nos enseña a transfigurar los objetos en ámbitos}

Si tenemos una mirada penetrante, el arte y la literatura de calidad nos descubren una verdad decisiva: que el auténtico entorno del hombre no esfá formado por objetos yuxtapuestos sino por ámbitos entretejidos. Ortega acuñó una frase que hizo fortuna - "Yo soy yo y mi circunstancia" - a fin de subrayar el carácter relacional de la vida humana. El hombre se realiza en constante interacción con cuanto lo rodea, porque es un "ser de encuentro". Nada más cierto. Pero falta por determinar el punto crucial: cómo han de ser las realidades que el hombre trata para poder encontrarse con ellas en sentido riguroso. El encuentro significa un entreveramiento fecundo, un intercambio de posibilidades. Este intercambio y ese entreveramiento sólo son posibles entre ámbitos, no entre objetos.

Las grandes obras literarias nos lanzan la mirada en todo momento hacia los acontecimientos que constituyen la trama de la vida humana, vista con hondura. No se reducen a narrar simples hechos. Si hoy seguimos emocionándonos con la Antigona de Sófocles, no es porque entre una joven y un gobernante griegos de hace veinticinco siglos haya habido un conflicto grave que determinó la muerte del más débil, sino porque entraron en colisión dos ámbitos de vida: el de la piedad y

3 Cf. Der Ursprung des Kunstwerkes, en Holzwege (V. Klostermann, Frankfurt/M. 1957, p. 21-22). 
el de la ley. Estos ámbitos forman parte de nuestra vida actual, y pueden dar lugar a colisiones dramáticas.

También el arte intensifica nuestra mirada para que no se detenga en la vertiente objetiva de los seres, antes penetre hasta su condición de ámbitos. En su conocido grabado Manos orantes, Durero no quiso únicamente reproducir la figura de unas manos humanas sino plasmar un ámbito de súplica.

Te vas a Toledo y admiras en la sacristía de la catedral el cuadro de El Greco El espolio. Adviertes que el rojo escarlata de la túnica de Jesús destaca su figura y la hace adelantarse. Ese efecto saliente es moderado por el azul del manto de María, que contempla asustada el agujero que un criado está abriendo en la cruz. Pero no te quedas en los pormenores de la composición del cuadro. Pasas més allá. Descubres que el artista no sitúa las figuras en un espacio físico; crea un ámbito espiritual de odio en torno a Jesús, y a Este lo destaca para hacer resaltar su increible soberania de espíritu que le hace posible distanciarse de sus intereses particulares y mirar extáticamente hacia lo alto en actitud indulgente. Todo el temple de Jesús ante la pasión quedó plasmado de forma inigualable en esta obra, a la que El Greco amaba tan intensamente que retomó el tema varias veces. ¿Quién podría afirmar que ese mundo asfixiante de odio, por una parte, y de libertad interior, por otra, es una mera ficción artística? Es un mundo real, dotado de un modo de racionalidad propia y de una forma de rigor específico. Pero este rigor, esta racionalidad y esta realidad sólo pueden captarlos quienes tengan poder de penetración para leer el lenguaje pictórico. Aprender a leer los diferentes lenguajes es presupuesto indispensable para pensar con rigor.

Repase el lector la serie de realidades y acontecimientos de la vida humana a los que aludi en el apartado anterior y verá cómo afluyen a su memoria cientos de obras literarias y artísticas que los han tomado como tema central. Podemos afirmar sin temor que tales temas han entrado por la puerta grande en la historia del arte y la literatura por ser ámbitos y no meros objetos. De ahí que su expresión artística y literaria constituya toda una "imagen" - que es bifronte, tiene relieve, remite a algo más allá de lo sensible - no una mera "figura" - que se reduce a una serie de rasgos sensibles carentes de profundidad. ${ }^{4}$

\section{4 - La contemplación de imágenes acostumbra nuestra mirada a trascender lo sensible}

Una de las tareas más fecundas del proceso formativo consiste en aprender a distinguir los diversos modos de realidad, otorgarles su rango y valor propios, y jerarquizarlos, es decir, conceder primacía a los más altos sobre los inferiores. Esta jerarquización sólo es posible cuando se adopta una actitud de "desinterés". Si me dejo llevar del afán de obtener ganancias inmediatas, me quedo preso en las realidades vistas como objetos; no me elevo a la consideración de las mismas como

4 El concepto de ámbito lo explico ampliamente en la Estética de la creatividad (Promociones Publicaciones Universitarias, Barcelona 1987, p. 163-291). Los ámbitos como tema primordial del arte es objeto de estudio en mi obra La experiencia estética y su poder formativo, Verbo Divino, Estella $1990 \mathrm{p}$. 11-73. 
ámbitos. Y, al reducirlas de esa forma, no puedo encontrarme con ellas y bloqueo mi desarrollo personal.

Por ser interesado, tiendo a dominar las realidades de mi entorno, no a respetarlas y colaborar con ellas de forma creativa. Pienso que yo estoy aquí y las otras realidades se hallan ahi, frente a mi, como algo distinto, distante, externo y extraño a mi ser. En consecuencia, temo que, si me entrego a tales realidades confiadamente, me pierdo y alieno. Tal temor me hace pensar que sólo puedo realizarme cabalmente si me recluyo en mi soledad egoista y me afirmo dominando y poseyendo.

Dominar y poseer sólo son posibles respecto a objetos. Y los objetos se hallan inevitablemente fuera del hombre; no pueden nunca llegar a serle ítimos. He ahí por qué profunda razón la actitud posesiva y dominadora nos induce a estimar que los esquemas aqui-alli, dentro-fuera, interior-exterior, independencia-vinculación, libertad-norma, autonomía-heteronomia, autoafirmación-solidaridad son siempre dilemas. No alcanzamos a descubrir la clave decisiva de la formación humana: que la actividad creadora convierte tales esquemas en contrastes, pares de conceptos que se contraponen y complementan entre sí. Esta deficiencia mantiene a millones de personas, sobre todo jóvenes, alejadas de la actividad creativa y, por tanto, de la plenitud personal.

\section{5 - "Libertad-norma" no constituye un dilema}

En esta encrucijada, la experiencia estética nos presta una ayuda sumamente eficaz: pone ante nuestros ojos de forma nítida, a veces sobrecogedora, la posibilidad de vincular fecundamente la libertad y la norma o cauce, la autoafirmación y la solidaridad, la autonomía y la heteronomía. Cierto día, en clase, me dijo una joven: "Profesor, no le dé vueltas. En la vida hay que escoger: o somos libres o aceptamos cauces. Gozar de libertad y estar sumiso a algo que te coarta desde fuera son aspectos de la vida totalmente opuestos. No tenemos más remedio que optar: o lo uno o lo otro. Y yo, por supuesto, escojo la libertad". Obviamente, esta joven no veia la forma de integrar la libertad y la aceptación de normas o cauces. Saber integrar aspectos diversos de la vida es un arte que debemos aprender. Si alguien lo desconoce, tiende a dar por supuesto que los aspectos contrastados de la existencia se oponen insalvablemente entre si. Le parece incuestionable que una cosa es ser libre y otra muy distinta, incluso opuesta, es aceptar normas y cauces. Por eso lo más urgente es mostrarle que tal integración se da de hecho en diversas vertientes de nuestra vida, por ejemplo, en la estética. Para ello dibujé en el encerado los pentagramas correspondientes al tema principal del cuarto tiempo de la Novena Sinfonía de Beethoven, y procuré que los alumnos se percataran de su carácter ordenado, geométricamente configurado, atenido a normas de la época sobre la composición de melodias. Estas características se advierten a simple vista, aún no conociendo la técnica musical. Tenemos 24 compases: cuatro y cuatro, cuatro y cuatro, cuatro y cuatro. Los cuatro primeros forman una pregunta, los cuatro siguientes configuran la respuesta. Pregunta y respuesta, a su vez, actúan de pregunta respecto a los ocho compases siguientes. Todo se halla perfectamente estructurado y reglado conforme a unas normas establecidas. A continuación les hice oir una bue- 
na interpretación orquestal de este pasaje, y les pregunté qué impresión les habia producido. La contestación fue unánime: una impresión de inmensa libertad, de espontaneidad creadora y soltura expresiva. Para que confirmaran la primera impresión de libertad expresiva, amplié la audición a las variaciones del mismo tema, en las cuales diversos instrumentos se unen al canto de los violoncelos y tejen un contrapunto admirable en el que no se sabe qué admirar más: si el dinamismo del tema inicial o la gracilidad con que se vinculan a él y se entretejen los diversos grupos de instrumentos. Tras las dos variaciones, la orquesta se aúna para entonar el tema con toda la decisión y rotundidad del estilo homofónico.

La conclusión de esta breve experiencia fue clara y aleccionadora: "¿Ven ustedes? - les dije a los alumnos. En la estética se vinculam del modo más eficiente la atenencia a normas y la libertad, el orden y la gracia, la delimitación precisa, casi rígida, y la soltura interna. No se puede dar por hecho que el concepto de libertad y el de norma o cauce se oponen y forman un dilema, que obliga a optar por uno u otro de ellos".

Comprobar esto dispone el ánimo para ser cautos en el campo de la Etica y no ver dilemas donde no hay sino contrastes. ¿Recuerdan lo que dice Kant de la palo$\mathrm{ma}$ El gran filósofo nos dio en una imagen una clave para configurar nuestra vida. Figúrense - advirtió - que una paloma, fatigada de tanto batir las alas contra el aire, renegara de la existencia de éste y deseara prescindir de él. Al querer una libertad absoluta, sin traba ni resistencia alguna, quedaria sometida a la fuerza bruta de la gravedad y caeria desplomada al suelo.

Permitanme añadir por mi cuenta: el que se empeñe en "liberar" sus pulsiones instintivas de todo cauce, que se opone a la absoluta libertad de maniobra, queda sometido a la fuerza de gravitación que arrastra al vértigo. Este arrastre seductor exalta el ánimo al principio, pero bloquea el dinamismo personal y provoca una desoladora decepción.

Esta decepción es la que sentiría, si pudiera pensar, el pez que fue sacado del agua por un mono que quiso "liberarlo" de perecer ahogado. ${ }^{5}$ El agua es el elemento en que se mueve el pez, su lugar natural de despliegue. En él se oxigena y vive plácidamente. El elemento propio del ser personal es un entorno de realidades valiosas a las que se siente vinculado y obligado. Desvincularse de ellas por afán de ser plenamente libre significa asfixiarse espiritualmente.

\section{6 - Al actuar creativamente, el esquema "autonomía-heteronomía" se convierte en contraste}

La vida ética de numerosas personas es paralizada por el temor - nunca bien revisado - de que la heteronomia - el actuar conforme a criterios recibidos del exterior - destruye de raiz la autonomía - la capacidad de regirse por criterios propios - y produce la alienación o enajenación, vale decir, la entrega a realidades externas y extrañas. Ciertamente, cuando uno adopta pasivamente normas de conducta que le vienen dictadas desde fuera, no actúa con autonomía personal; depende de quien le marca la vía a seguir. Su conducta es heterónoma, no autónoma.

5 Cf. A. de Mello: El canto del pájaro, Sal Terrae, Santander, 1987, p. 21. 
En este caso, el esquema "autonomia-heteronomia" es dilemático. Pero ¿lo es siempre? La experiencia estética nos permite vivir emocionadamente la conversión de este dilema en contraste.

Nos ponemos a cantar una obra polifónica. Cada voz entona su melodía con seguridad, con dominio, con poder configurador. Entra en la obra y sale de ella con toda espontaneidad, como si sólo dependiera de su decisión. Pero todo cantor sabe muy bien que esta espontaneidad y aquel poder no le vienen sólo de él, de su musicalidad, de su técnica interpretativa; surgen al contacto con la obra misma que está colaborando a gestar. Estamos ante una experiencia reversible, con su espléndida fecundidad. El cantor configura la obra al tiempo que es impulsado por ésta. Entra en la obra y sale de ella con la confianza de quien se mueve en su hogar propio. Actúa con libertad interior, merced al impulso que late en la melodía que interpreta; pero no es dueño de lo que hace, se siente inspirado por la vida interna de la obra en cuya gestación colabora. En esta experiencia reversible ostentan cierta autonomia tanto los intérpretes como la obra. Son centros de iniciativa que crean un campo de juego común. En este campo de juego nadie domina a nadie; todos se potencian y sostienen mutuamente. Por esa profunda razón, el compositor que estructuró la obra y le confirió una articulación determinada se siente muy agradecido a los cantores pues sin ellos esa trama sonora no existíía realmente, no cobraria cuerpo sensible. Y los cantores agradecen al compositor que les haya ofrecido un cauce eficaz a su capacidad interpretativa. Son plenamente autónomos al ser lúcida y agradecidamente heterónomos. Es decir: ganan libertad interior y seguridad en sí mismos cuando aceptan como impulso de su obrar una realidad que en principio les era distinta, distante y extraña. El que adopta una actitud creativa convierte el esquema "autonomía-heteronomía" en un fecundísimo contraste y adopta una actitud agradecida. El agradecimiento está en la base de toda experiencia reversible y, por tanto, de la vida personal vivida en plenitud.

\section{7 - El esquema "independencia-solidaridad" debe ser visto como "contraste"}

Un proceso de transformación semejante se realiza con los esquemas "independencia-solidaridad", "independencia-vinculación colaboradora". Empezamos a entonar una obra a varias voces. Cada voz se mueve con tota independencia respecto a las demás. Posee una dinámica propia, una belleza singular, un impulso interior que la lanza hacia adelante y la sostiene. Parece bastarse a sí misma. Ninguna de las otras voces puede alterar el curso de su melodía. Pero todo cantor, al tiempo que ejercita su libertad interpretativa, presta atención a la marcha de las otras voces para atemperarse a ellas: a su ritmo e intensidad, a su volumen y expresividad... De esta forma, actuando con independencia y solidaridad a la vez, las voces crean, entre todas, un conjunto armónico de belleza sobrecogedora. En efecto, sobrecoge observar que la melodía que yo entono cobra toda su potencia expresiva y su sentido cabal cuando se abre a las demás, entrevera sus virtualidades expresivas con las suyas y funda ese fenómeno sorprendente y originario que es la armonía. Imagínense el empobrecimiento que supondría para cada una de las voces si cayeran en la tentación de cerrarse en sí mismas para salvaguardar su independencia. Tendrian razón al pensar que son independientes, que deben desple- 
garse conforme a un impulso que brota en su interior, que tienen derecho a recorrer su camino sin que nadie lo altere desde fuera. Pero se equivocarían al concluir que independencia implica oclusión, cerrazón, insolidaridad. Uno llega a ser de verdad independiente como persona cuando vive solidariamente, y la solidaridad auténtica se gana al participar en tareas comunes valiosas.

¿Han visto alguna vez un buen coro y una excelente orquesta actuando conjuntamente? Supongamos que se trata de los intérpretes que nos ofrecen una magnifica versión del Oratorio de Navidad de J. S. Bach bajo la dirección de N. Harnoncourt. Niños y mayores aparecen transportados. Hay algo que los eleva a una región superior y los une entre sí. Ese arrebato, ¿los saca fuera de sí, en el sentido de que les quita serenidad, conciencia de su propia identidad personal, y los deja entregados a una fuerza exterior incontrolada? De ningun modo. La realidad que los arrebata suavemente - la obra de Bach - los entusiasma pero no los seduce; los atrae hacia sí, concentra todas sus fuerzas en la tarea de darles vida, pero no los enajena, nos los entrega a algo distinto y distante, porque la obra en ese momento se les ha hecho íntima. Es su voz interior. Y a ella se sienten unidos con un modo de unión elevadísimo, pues nada nos es más íntimo que lo que constituye el impulso de nuestro obrar. Nos asombra contemplar a ese centenar de músicos que actúan con una unidad perfecta y dan lugar a una obra de belleza impresionante. ¿De dónde procede tal modo de unidad fecundísima? De la relación reversible que cada intérprete mantiene con la obra interpretada. El director no arrastra a los intérpretes. Los aúna en la contemplación de la misma obra; los lleva a verla desde una perspectiva determinada, la más justa a su entender. Una vez que adoptan la misma perspectiva para ver la obra e interpretarla, es la obra misma quien realiza el prodigio de ensamblarlos a todos en una tarea común. Es posible que algunos intérpretes, en su vida diaria, se hallen escindidos por graves divergencias entre sí y con el director. Al insertarse en el campo de juego común que es el acto interpretativo, superan el plano en que se dan tales escisiones y ganan una unidad ejemplar.

\section{8 - Necesidad de fundar los modos más altos de unidad}

La tarea decisiva de la formación consiste en descubrir el modo como podemos los seres humanos fundar los modos más elevados de unidad con las realidades circundantes: personas, instituciones, obras culturales, tradición, pueblos, paisajes, valores de todo orden... Acabamos de ver que la experiencia estética nos ofrece pistas certeras para realizar tal descubrimiento. Su fecundidad en este aspecto es sorprendente. Analicemos otro ejemplo.

El gran escultor francés A. Rodin puso por titulo "La catedral" a una escultura que no consta sino de dos manos humanas. ¿Hemos pensado alguna vez a fondo en el sentido de tal denominación? Se trata de dos manos derechas, pertenecientes a dos personas de distinto sexo. Se hallan a punto de entrelazarse y formar un espacio físico de unión y un espacio lúdico de amparo. Todo cuanto significa el encuentro humano vibra luminosamente en estas dos manos broncíneas que perpetúan el gesto de acercarse con voluntad de comunicación y entreveramiento. Con- 
frontemos este tipo de acercamiento con el que tiene lugar en la bóveda de una catedral que está a punto de concluirse.

En la catedral gótica diversas columnas se alzan desde lugares diferentes, ascienden a lo alto, siguiendo cada una su camino propio. Al ganar cierta altura, se bifurcan, se entretejen en la bóveda y forman una trama de nervaduras. Estas contrarrestan las cargas del techo, y las orientan hacia las columnas, y hacia los arbotantes y pilastras, que ofrecen su colaboración desde el exterior. Al realizar tal función, ineludible para el sostenimiento del edificio, estos elementos - columnas, nervios, bóvedas - fundan un espacio físico unitario, acogedor y bello. Está compuesto de mil y un elementos, pero todos confluyen en una imagen de perfección al dejarse orientar e impulsar por el ideal común de fundar un ámbito de unidad.

$\mathrm{Al}$ reunirse en este campo de juego espiritual, los creyentes transforman el espacio físico en espacio lúdico, en campo de encuentro religioso, en ámbito. El creyente que está empapado del ideal religioso capta al mismo tiempo estos dos sentidos del espacio - el físico y el lúdico - porque vive simbólicamente, es decir, experimenta en su propio ser el entreveramiento de la realidad natural y la sobrenatural.

El ámbito creado por el entrelazamiento de los elementos materiales y transfigurado por la luz solar que se tamiza a través de las vidrieras es visto como una plasmación sensible del ámbito espiritual que se constituye al unirse en la iglesia los fieles bajo el impulso de un mismo Espíritu. Los frutos del encuentro - alegria, entusiasmo, felicidad, júbilo festivo, luminosidad, amparo - resaltan gloriosamente en este ámbito de altísima unidad que se forma entre los creyentes y entre ellos y el Creador al que adoran conjuntamente. La armonia arquitectónica florece aquí en un género de encuentro desbordante de sentido y de belleza.

Siempre la unidad, el orden, la armonia van hermanados con el surgir de la belleza, que los antiguos definian sabiamente como el "esplendor del orden, de la forma, de la realidad". "¡Oh Catedral, yo te edificaré en el corazón del hombre!", exclamaba Saint-Exupéry, que en su magna obra póstuma Citadelle quiso crear una catedral literaria, un lugar de amparo y plenitud humana. La clave de bóveda que sostiene esa catedral edificada en el corazón del hombre es el acto de encuentro, entendido con todo rigor. Si este acto falla, se desmorona el conjunto, y cada uno de los elementos pierde su sentido cabal.

La clave de bóveda es un punto de confluencia en el que vibra la tensión de cada elemento hacia la unidad. Visto desde la clave de bóveda, cada elemento es un nudo de relaciones. Esta es justamente la idea que se tiene de cada ser cuando se lo ve a la luz del ideal de la unidad. La armonía, el ensamblamiento mutuo lo sostiene todo y lo embellece.

Volvamos a la obra de Rodin. Dos manos que se hallan en situación de cercanía y dirigidas hacia lo alto pueden presentar diversos sentidos. En una escultura denominada "La Catedral", van obviamente buscando la clave de bóveda del gran edificio que es el hogar. Una catedral supone el lugar por excelencia de encuentro de los creyentes.

Considerar como una catedral la unión de un hombre y una mujer, simbolizados por su mano derecha, entraña una concepción del amor conyugal como un ámbito que afecta a las raíces mismas de la realidad humana y presenta una afinidad 
extrema con el mundo de lo sacro, que, bien visto, es un tejido de relaciones valiosísimas de encuentro.

Esta obra de Rodin es simbólica y sugerente porque plasma un ámbito de encuentro y remite a la meta última de la vida humana, meta que consiste en fundar los modos más elevados de unidad con las realidades del entorno.

¿Ven ustedes cómo las obras de arte, por integrar dos modos de realidad, tienen un largo alcance, no se reducen a una bella superficie halagadora para la sensibilidad?

\section{9 - La formación humana consiste en orientarse hacia el ideal de la unidad y solidaridad}

El ser humano se orienta hacia la madurez personal cuando encamina su vida hacia el ideal que responde a las exigencias más hondas de su propia realidad. De ahí que la tarea crucial de la actividad formativa consista en averiguar cuál es el ideal propio de un ser personal y conferir a la voluntad la decisión necesaria para asumirlo en la propia existencia y realizarlo.

Esta doble tarea sólo es posible si nos percatamos de que el afán de dominio nos impide ser creativos; aumenta nuestras posesiones, nuestra capacidad de mando, nuestra área de influencias, el número de gratificaciones que podemos disfrutar, pero nos aleja de toda acción rigurosamente creadora e impide nuestro desarrollo personal. En cambio, la decisión de fundar generosamente modos elevados de unidad con las realidades circundantes nos pone en la vía de nuestra plenitud personal.

Para realizar este giro del ideal de dominio al ide:il de colaboración solidaria es indispensable convencerse de que en él se juega nuestro ser de personas, pues ser persona y actuar creativamente se implican. Es, por ello, sumamente fecundo para la formación comprobar por propia experiencia que la actividad creativa implica "desinterés", por cuanto se da entre realidades que no intentan dominarse mutuamente sino potenciar sus posibilidades y dar lugar a una nueva realidad valiosa.

Tal comprobación se lleva a cabo de modo luminoso el la experiencia de interpretación musical. Rehagámosla y advertiremos, sorprendidos, que nuestros esquemas mentales y nuestras coordenadas espirituales se trasmutan, nos elevamos a un nivel de actuación más alto, más fecundo y libre. Tomo la partitura de una obra que desconozco y la pongo sobre el atril del piano. La partitura se halla cerca de mí. La obra musical está todavia lejos; es para mi algo distinto, distante, externo y extraño. Sin embargo, a través de los signos de la partitura se me revela de alguna manera, aunque sea borrosa, me manifiesta su riqueza de formas, y me invita o apela a que le otorgue un cuerpo sonoro sobre el piano, es decir, que la traiga a la existencia. Esa petición, por parte de la obra, a que yo asuma su valor y lo realice impulsa mi capacidad pianística, y empiezo a ensayar. En este ensayo acontece algo muy notable: Voy buscando una realidad que todavía desconozco en virtud del impulso que me viene de ella misma. Parece una paradoja, pero nos revela una verdad muy fecunda. Siempre que vamos en busca de algo, actuamos con la fuerza que procede de un valor entrevisto que nos hace presentir una gran riqueza. Sentimos confianza en él y tenemos esperanza de poder asumirlo y enriquecernos. 
Movido por tal esperanza, voy recreando tanteantemente sobre el teclado las formas de la obra que adivino a través de la partitura. Lo hago con timidez, sin soltura, caminando entre la niebla. Poco a poco, las formas se van precisando más y más, conectando unas con otras, formando frases y configurando los diversos tiempos. Esta configuración se la otorgo yo, pero es de las formas, que poseen una fuerza expresiva propia. En realidad, yo configuro la obra en cuanto me dejo configurar por ella. Avanzo en la interpretación de la misma al dejarme iluminar por la luz que ella desprende. Al interpretar cada pasaje, la obra misma me indica si su fuerza expresiva está ya al descubierto, plenamente operante, o si mi forma de tocar no ha descubierto aún su plenitud de sentido. Profundizo una y otra vez en cada pormenor, hasta que una especie de voz interior me advierte que cada forma musical está poniendo en juego toda su expresividad. En ese momento tiendo a decir que "domino" la obra, me muevo con libertad absoluta por sus avenidas, resuelvo con éxito sus dificultades técnicas, la revelo plenamente a los oyentes. Pero he de volver sobre mis pasos y reconocer que el verbo dominar es aquí improcedente. No puedo decir que domino la obra cuando es ella la que está inspirando mi acción, modelándola, rigiéndola, determinando cuándo es ajustada o equivocada. En rigor, una obra que ha de ser re-creada no puede ser dominada. Gravémoslo bien: En los procesos de creatividad nadie domina a nadie; todos se potencian mutuamente al intercambiar posibilidades de acción.

En este momento de plena configuración mutua, se invierten las relaciones de inmediatez y distancia que se daban al principio entre el pianista, la partitura y la obra. Al convertirse ésta en principio modelador e impulsor de la actividad del intérprete, deja de ser distante, externa y extraña a éste, aún siendo distinta, para tornarse íntima. De esa forma, el intérprete no obedece ya a una realidad exterior la partitura - es inspirado por una realidad que ha hecho suya, y lo es plenamente en el sentido profundo de que la vive como propia, se deja modelar por ella, y ella a su vez necesita de su actividad para existir en acto, no sólo virtualmente. Por todo ello, la fidelidad del intérprete a la obra no implica una entrega del mismo a una instancia externa, extraña, impositiva, sino la voluntad de realizar un diálogo creador con una realidad que es al principio externa y extraña pero está deseando convertirse en intima.

Hacerse intima una obra significa que se hace presente. Los elementos que moviliza el pianista para interpretarla constituyen el medio en el cual la obra se revela. Y se revela de forma inmediata, como lo hace una persona cuando sonríe. La técnica que posee el pianista es puesta en juego, pero no se hace ver. La partitura sigue ahí orientando la actividad del intérprete, pero éste ya no la mira, porque es la obra misma la que canta en su interior, la que constituye su fuerza configuradora de formas. Podemos decir que todos los elementos que hacen posible la interpretación de la obra entran en estado de transparencia. Siguen ahí, operantes, pero en un discreto segundo plano. No imponen su presencia. Son el medio en el cual la obra y el intérprete entran en relación de presencia, se comunican, se enriquecen, se actualizan; la una como obra, el otro como pianista. "Entre la esencia musical de la pieza tal como está indicada en la partitura - escribe el gran fenomenólogo $\mathrm{M}$. Merleau Ponty - y la música que suena efectivamente alrededor del órgano se esta- 
blece una relación tan directa que el cuerpo del organista y el instrumento no son más que el lugar de paso de esta relación".

Esta trasmutación que se opera en los elementos que sirven de mediadores en una actividad creativa encierra el mayor interés para la formación humana. Pone de relieve el hecho decisivo de que para alcanzar un desarrollo perfecto en cualquier orden de actividad debemos.tener bien ante la vista la meta a conseguir, el ideal a realizar, y todos los medios que hayamos de movilizar para ello deben ser puestos a pleno rendimiento pero no han de ser idolatrados; han de convertirse en algo translúcido, leve, lugar viviente de la presencia del ideal alcanzado.

Piense el lector en la fecundidad de esta conversión no sólo en la vida estética sino también en la ética y la religiosa. El saber teórico, el poder técnico, los recursos económicos, las potencias sensibles... desempeñan un papel ineludible en distintas actividades humanas. Si queremos que el papel que juegan sea fecundo y no perturbador, no debemos tomar como una meta el halago que produce la sensibilidad, el confort, la holgura económica, y fusionarnos con él fascinadamente. Hemos de estimarlo sobre todo por ser un detector de valores más altos.

\subsection{0 - El arte nos descubre un modo de transfigurar la vida}

Nuestra vida de hombres adquiere todo su relieve y su brillo cuando nos habituamos a ver las realidades como ámbitos, no solo como objetos. De ahí la necesidad de aprender a elevar los objetos a condición de ámbitos. Por vía de ejemplo, consideremos una consola de órgano. Constituye un espacio físico, acotado por una serie de elementos: un banco, un pedalier, innumerables registros, teclados manuales, palancas... ¿Cómo se presenta esta multiplicidad de objetos a quien no sabe tocar? Como algo monótono, desesperadamente igual, desorientador. El que desconoce la técnica del órgano y no domina el arte de crear formas musicales en su consola intuye que se le ofrecen miles de posibilidades pero no sabe asumirlas activamente. No puede ser creativo en ese entorno. La consola se reduce para él a un espacio físico muy complejo en el cual no sabe qué hacer.

Para el organista, en cambio, nada es igual en la consola. Cada nota, cada registro, cada palanca tiene un papel determinado que cumplir. Una nota parece igual a otra. Efectivamente lo es, en el aspecto físico. Pero en el juego de la interpretación desempeña una función muy distinta El que tiene sensibilidad musical capta con extremada finura esa diferencia. Entre las notas y los registros se establecen mil relaciones posibles que darán lugar a formas musicales de todo orden. La consola no es vista por el experto como un mero espacio físico abarrotado de elementos irritantemente iguales. Para él es un campo de juego artístico, que le invita a actuar creativamente.

$\mathrm{Al}$ ver el espacio físico como un espacio lúdico, todo cobra un valor peculiar, entra en relación, funda orden, se jerarquiza, se satura de sentido y se torna comprensible. En ese entorno así cambiado, el hombre puede ser creativo, crear ámbitos de encuentro y dar origen a realidades nuevas: las obras musicales que interprete. 
Ahora podemos comprender por qué tiende el hombre a convertir los objetos en ámbitos y los espacios físicos en espacios lúdicos. Es por el afán de ser creativo, de instaurar modos elevados de unidad con los seres del entorno y fundar, asi, cultura. El niño se encabalga sobre un palo de escoba y lo convierte en caballito; establece con él una relación de unidad muy honda y llena de sentido. Dos hermanitos se sitúan en un rincón de la casa y lo transforman en un campo de juego.

Toda la vida del hombre está montada sobre la transformación de lo físico en lúdico. Vas a una ciudad desconocida y te parece un desierto. No estableces relaciones, no fundas ámbitos de convivencia. De repente, recibes una llamada telefónica de un viejo amigo que se enteró de tu estancia en la ciudad y te invita a comer con él. Este sencillo gesto reaviva una vieja amistad, en la cual se supera esa escisión entre el aquí y el allí, el dentro y el fuera. Tal superación transforma la ciudad entera, la "ambitaliza" en alguna medida, siquiera mínima. La inmensa urbe adquiere con ello un carácter humano, se dinamiza, se carga de valores.

La experiencia artística nos insta a elevarnos al plano de los ámbitos sin perder el de los objetos, sino trascendiéndolo. Esta elevación es descrita certeramente por el esteta francés Denis Huisman: "Oigo el Sexto concierto de Brandenburgo: la polifonia de las violas solistas no me impide contemplar las tapicerías rasgadas, estas viejas colgaduras de la sala del conservatorio. Pero de golpe, en un instante, ya nada existe. Ni sala. Ni público. Nada más que la sola presencia del sonido que es la presencia misma de Bach. Yo no estoy solo. Es un diálogo que me ha sustraído a las condiciones exteriores de la existencia. ¿Qué se ha hecho de la sala? Ya no existe para mi porque todo lo material ha huido. Y la percepción visual de los ejecutantes, la sensación auditiva de los instrumentos se han trocado, por una transformación radical, en un sentimiento que me transporta más allá de mí mismo: el éxtasis [...]" "[...] De un lado se siente una alegría extática, que no es sino extremo contentamiento, y, de otro, hay una especie de rapto o desgarramiento respecto a las condiciones temporales de la vida. Pero estos dos sentidos no hacen mas que uno". "La alegria es el más puro de los consuelos; porque el arte o es consolador o no es arte".?

Fijémonos bien en cómo se opera la transformación estética a que alude Huisman. Mientras estamos en la sala sin adentrarnos en una obra musical, tenemos con cuanto nos rodea una relación "lineal", no reversible. Yo estoy aquí, y ahí, frente a mí, se hallan las cortinas, los instrumentos musicales, las lámparas, las demás personas, a las que no me une en este momento otro vínculo que el puramente circunstancial de hallarnos en un mismo recinto, esperando un mismo acontecimiento. Yo lo veo todo como desde fuera, desde la lejanía, y cada realidad aparece crudamente tal como es, sin transfiguración alguna.

Pero empieza la audición de una obra muy valiosa, y establezco con ella una relación reversible. La asumo como propia, la vivo, la recreo interiormente. Al fundar entre ambos un campo de juego, la obra deja de estar fuera de mi, frente a mi, para entreverarse conmigo de modo enriquecedor. Este entreveramiento es un suceso de gran riqueza que pertenece a un nivel de realidad más alto que las sillas, las cortinas, los instrumentos e incluso que otras personas, vistas aquí sencilla- 
mente como público; como realidades que forman un conjunto de espectadores, de los que me veo físicamente rodeado. De ahí mi impresión de que todo ello desaparece. No es que desaparezca; sigue ahí intacto. Lo trasciendo en cuanto me elevo a un nivel superior de experiencia. Es la experiencia de éxtasis, que supone siempre un salto de un nivel de realidad o de actividad a otro superior. Este salto no supone un rapto en sentido de arrebato. Yo no soy arrebatado a ese nivel de experiencia elevada como la pluma es arrebatada por el viento, la barca por la riada o el hombre hedonista por algún tipo de vértigo. Yo me alzo a dicho nivel de forma lúcida y libre, gozosa y entusiasta.

\subsection{1 - La afinidad de la experiencia estética con las experiencias ética, metafisica y religiosa}

Tanto en la experiencia estética como en la ética, la metafísica y la religiosa buscamos algo en virtud de la fuerza que irradia la realidad buscada, nos ponemos en marcha hacia algo que nos apela porque de alguna manera ya estamos instalados en ello. Esta forma de presencia primaria, tan potente como imprecisa, pide ser perfeccionada y hace posible, a su vez, tal perfeccionamiento. Una obra musical se deja adivinar a través de la fronda de las notas de la partitura a la primera ojeada. Esta presencia inicial es sin duda más pobre que la obtenida por el intérprete cuando culmina el proceso de aprendizaje y configura la obra a perfección. Pero sin ella no sería posible todo este proceso creador de la obra.

Algo análogo sucede en las experiencias ética, metafísica y religiosa. El hombre se halla instalado en lo real. En cada momento de la vida puede adivinar la riqueza y poder de la realidad que funda su ser y el de cuanto lo rodea, y sospechar el poder fecundante de la acción humana que poseen los grandes valores. Esta adivinación germinal impulsa todo un proceso de búsqueda. El hombre asume los poderes que la realidad le otorga y acepta las virtualidades que los valores le facili$\tan$. Al hacerlo, adquiere un conocimiento más preciso de lo que implican los valores y la realidad. Este mayor conocimiento le permite afinar la sensibilidad para oir la apelación de los valores y la voz de la realidad, y darles cumplida respuesta. De esta forma, a través de distintas apelaciones y respuestas, el hombre entra en relación de presencia con los valores y con la realidad, y se eleva a lo mejor de su ser como persona.

He aquí cómo la experiencia artística, debidamente realizada y comprendida, nos da torrentes de luz para descubrir la articulación interna de otras experiencias humanas, más dificilmente accesibles - al menos en muchos casos - y nos permite entrañarnos en ellas.

\section{2 - Condiciones para que se dé la fecundidad formativa de la experiencia artística}

La experiencia artística ejerce una función formativa eminente cuando se la vive de forma integral, sin despojos injustificados, en toda su riqueza y complejidad.

Una obra de arte puede considerarse cabal, completa, cuando asume en sí de forma estructural estos ingredientes: 
1. Los materiales, elementos físicos objetivos, es decir: mensurables, calculables, situables en el tiempo y el espacio.

2. Los materiales engarzados entre si y dotados, por ello, de una expresividad nueva, merced a esa forma de causalidad singular que es la causalidad situacional.

3. Los materiales entreverados y estructurados mediante el poder cohesionante de una forma.

4. La representación de figuras o acontecimientos naturales, y la plasmación expresiva de ámbitos en "imágenes". Como hemos visto, la meta del arte no es tanto reproducir figuras cuanto plasmar ámbitos. Al advertir esto, se supera la interpretación superficial del concepto de "mímesis".

5. La expresión oblicua del estilo de vivir y pensar del artista, es decir: de su mundo cultural. Una obra de arte puede parecer un puro juego de formas. Vista con profundidad, revela todo un mundo, el estilo de vida de la época en que fue gestada. En una pieza clavecinística de Couperin, por ejemplo, vibra todo el estilo galante de la Francia de su época.

6. El entorno propio de cada obra de arte; el tejido de relaciones dentro del cual adquiere su plenitud de sentido.

7. El poder emotivo de la obra, su capacidad de despertar en toda persona sensible determinados sentimientos espirituales.

\section{1 - Necesidad de una mirada integradora}

La formación estética consiste en habituarse a no prender fascinadamente la atención en los elementos sensibles, y ganar libertad interior para descubrir la vinculación intensa de los siete elementos o planos de la obra artística. De abajo arriba y de arriba abajo se da una vibración mutua entre tales elementos. En cada elemento sensible está operante el mundo que en él se encarna, con todo el entorno al que pertenece y que le nutre. Este entorno y ese mundo están pidiendo de por sí un material sensible adecuado para plasmarse luminosamente. Por otra, "la materia está pregnante de la forma" (Merleau-Ponty), pide una forma determinada. En toda obra de arte, lo llamado material y lo espiritual se influyen mutuamente.

En la creación artística se da, asimismo, un influjo mutuo entre la capacidad técnica y la vida espiritual. Puede afirmarse, sin embargo, que en el orden cronológico ésta precede a aquélla. Primero se forma una mentalidad determinada, debido a la confluencia de diversas circunstancias históricas; en un segundo momento, personas especialmente dotadas elaboran una técnica adecuada para plasmar en obras de arte esa forma peculiar de pensar, de sentir, de ver el universo. ${ }^{8}$ El hombre gótico no adelgazó los muros porque disponía de una técnica suficiente para orientar las cargas hacia otros puntos de gravitación. Adquirió esta técnica porque deseaba vincular el ámbito exterior y el interior y fundar un ámbito nuevo transfigurado mediante la luz natural tamizada al atravesar las amplias vidrieras.

8 Un estilo artistico o literario no es mero producto del esfuerzo realizado por uno o varios seres dotados de una capacidad genial de creación. Es el fruto de la confluencia de diversas realidades y acontecimientos que se potencian mutuamente. Véase sobre esto mi Estética de la creatividad, p. 259363. 
Los arquitectos de El Escorial sustentaron la poderosa cúpula y la bóveda ingente en pilastras y muros de una impresionante densidad. No lo hicieron por desconocer la técnica gótica de adelgazamiento de muros y columnas, sino porque sentian el gusto de los materiales graves y deseaban crear un ámbito interior sacro netamente separado del ámbito externo profano.

La arquitectura, vista en su génesis, nos ofrece mil ejemplos de cómo el principio inspirador e impulsor de toda construcción artística es el deseo de dar cuerpo sensible a una actitud espiritual.

Revivir genéticamente una obra artística, como si se la volviera a gestar, y sentir las diversas formas de emoción que suscitan los diversos elementos que la integran son acontecimientos correlativos que se exigen mutuamente. Depreciar la emotividad como un residuo romántico espurio sólo es posible cuando se considera la obra de arte como mero producto de un proceso artesanal, y no como fruto de un encuentro del artista con la realidad circundante.

Esta actitud reductora lleva a ignorar los modos de sentimiento superiores y a considerar como únicas formas de sentimiento la de lo agradable y la de lo repulsivo. Naturalmente, como estas formas se hallan en los peldaños más bajos de la escala de valores, resulta fácil prescindir del sentimiento y consagrar toda la atención a la producción arbitraria de objetos artísticos. De ahi se sigue la primacia concedida al esfuerzo sobre la inspiración.

Una de las tareas primarias de la estética actual es, sin duda alguna, revalorizar el papel de la emotividad, rectamente entendida. Ya se han realizado beneméritos intentos en ese sentido, ${ }^{9}$ pero todavia no se ha llevado a cabo una clarificación del valor de los diversos tipos de sentimiento a la luz de una teoría del juego y de los ámbitos.

\section{2 - La precariedad de ciertas obras de arte}

Sobrevolemos todo lo antedicho. Las obras artísticas integran diversos modos de realidad. Esta integración halla su clave de bóveda en la plasmación de los acontecimientos interaccionales en los que se entreveran diversos ámbitos para fundar un ámbito superior. A esta luz queda patente el sentido pleno de las realidades que se ensamblan y acrecientan, al ensamblarse, el acervo de la realidad. La patentización de las vertientes de la realidad que deben su origen al entreveramiento fecundo de ámbitos constituye la forma peculiar de verdad que ostenta el arte y la razón básica de su racionalidad específica.

Los artistas, los intérpretes y los contempladores de las obras de arte pueden conceder primacia a unos estratos de la obra sobre otros, o atender a unos y cultivarlos mientras dejan a otros de lado. Esta unilateralidad no elimina del todo la obra artística, pero la depaupera en una u otra medida. Tienen razón cuando hacen valer su derecho a orientar su vida estética del modo que les resulta más sugestivo. Se equivocan, sin embargo, cuando intentan convertir su gusto personal en canon de autenticidad.

\& Cf. Th. Haecker, Metaphysik des Fühlens, Kösel, München 1955. Bd. castellana: Metafisica del sentimiento, Rialp, Madrid 1959; A. Roldán, Metafisica del sentimiento, CSIC, Madri 1956. 
La existencia de siete estratos en la obra de arte ofrece al artista una amplia gama de posibilidades para poner el acento en uno $u$ otro y dar lugar a orientaciones diversas en la configuración de obras. Esta diversidad de vias creativas implica una gran riqueza. La estima de la misma no debe llevarnos, sin embargo, a juzgar que todas las concepciones del arte son igualmente válídas.

Un estudio sereno de los valores que encierran las obras artísticas nos descubre que las obras maestras, las que constituyen las más altas cimas del arte universal, integran en si los siete estratos o niveles que hemos descrito anteriormente y que, a su vez, se conectan con otros de gran significación. Asi, el estrato quinto se halla en vinculación genética con el nivel simbólico, ya que el símbolo brota dinámicamente en el entreveramiento de ámbitos.

Si una obra no plasma ámbitos y encarna todo un mundo cultural, un estilo de vida, carece del poder de remitir a lo que trasciende lo sensible: lo trascendente y misterioso.

Este tipo de obras despojadas de los elementos expresantes (los ámbitos y el mundo) quedan "desambitalizadas". Dado que el entorno humano auténtico está constituído no tanto por objetos cuanto por ámbitos interconexos, tales obras presentan un carácter "deshumanizado". No se debe la deshumanización al hecho de no representar figuras de realidades objetivas o hechos de la vida cotidiana. Esta forma de representación no es esencial al arte. Lo esencial es reflejar algun aspecto, por sencillo que sea, del mundo humano, que es sensible y espiritual a la par. El gran compositor suizo contemporáneo Frank Martin lo expresa con energia: "Es necesario absolutamente, a mi juicio, que haya algo que trascienda la perfección estética". "Estoy convencido, y es una especie de fe en mi, que hay algo distinto que debe venir a trascender la belleza estética y el equilibrio plenamente realizado de la obra perfecta; no hay otro término para hablar de ello que el de ética". ${ }^{10}$

Con el mismo afán de conceder a la obra de arte todo su alcance, escribe el fenomenólogo suizo J.Ćl. Piguet: "Es un hecho que el criterio de valor del que se echa mano comúnmente hoy día para juzgar una obra musical se resume más o menos en estas palabras: 'está bien compuesta y suena bien', lo que es reducir el valor de la música a los niveles estético y auditivo, en detrimento del valor ético. La Poética musical de Strawinsky dio un cuerpo teórico a este estado de cosas: deja de lado voluntariamente la intención ética de la obra, para reducirla a las astucias del oficio y al juego de los timbres orquestales". "Reducida a una ordenación estética de valores sonoros, la música pierde la dimensión ética que daba a la estética y a lo sonoro su justo valor. Olvidaria lo esencial, y lo olvida a veces voluntariamente". ${ }^{11}$

El análisis de la estructura de la obra de arte nos permite comprender a fondo varios puntos del mayor interés:

1. La fecundidad formativa del arte.

2. La falta de carácter "simbólico" de ciertas obras, su reclusión en sí mismas y su consiguiente "frialdad" o falta de emotividad.

10 Cf. F. Martin y J. Cl. Piguet: Entretiens sur la musique, A la Baconnière, Neuchatel 1967, p. 123.

11 Cf. Emst Ansermet et les fondements de la musique, Payot, Lausanne, 1964, p. 56. 
3. Las condiciones que debe tener una obra de arte que quiera suscitar un sentimiento de elevación religiosa. No debe preocuparse tanto de adquirir la "pureza" del arte "no figurativo" (mal llamado "abstracto") cuanto de vibrar con realidades altamente valiosas.

4. El secreto para conseguir obras de arte relevantes es que las personas bien dotadas se esfuercen en "participar" de los valores más altos. Esto exige una actitud de sencillez y de colaboración, opuesta a toda forma de individualismo altanero.

Tal actitud puede privarnos de "individualidades" notables, pero nos otorgará "personalidades" eminentes, al modo de las que todavía hoy admiramos en los sencillos maestros del románico, que no intentaron imponer su capacidad de iniciativa sino reflejar fielmente el mundo estético y espiritual en que alentaban. Por eso nos dejaron obras que nos hacen vibrar y enriquecen nuestra vida. ${ }^{12}$

La crisis ética y la religiosa significan una falta de participación en realidades valiosas $y$, consiguientemente, una carencia de experiencias reversibles. Rotos los lazos con el entorno más valioso del hombre, el artista se queda a solas con sus ideas, sus sentimientos, su imaginación. En tal soledad agostadora puede "producir" objetos artísticos, pero dificilmente será capaz de "crear" obras sacras en las que podamos encontrarnos y participar fecundamente, y con las que podamos así encontrarnos.

En más de una iglesia construída conforme a las directrices del arte sacro contemporáneo, el arquitecto colocó en el altar mayor un Cristo tallado hace siglos. Los productos del arte actual no le parecian adecuados al culto. ¿A qué se debe tal inadecuación? Sin duda, a la falta de luz que brota en el encuentro, el encuentro con las realidades altamente valiosas que constituyen el auténtico entorno del hombre visto en todo su alcance.

12 Sobre estos temas pueden verse mis obras: Hacia un estilo integral de pensar. I. Estética, Bditora Nacional, Madrid 1967, p. 264-295, La expeniencia estética y su poder formativo, Verbo Divino, Estella 1991, p. 106 ss. 